\title{
The Construction of the Tea Culture Communication System with Chinese Characteristics from the Perspective of "the Belt and Road Initiative"
}

\author{
Tang Minghui \\ China Jiliang University, Xiasha, Hangzhou, China \\ 1316572043@qq.com \\ Guo Lanying
}

Keywords: "the Belt and Road Initiative," tea culture, communication system

\begin{abstract}
The Belt and Road Initiative" is a new cooperation model proposed by China, the construction of "the Belt and Road Initiative" has provided greater space for Chinese culture to the world. An important commodity in China's ancient Silk Road is Chinese tea, the trade of Chinese tea has promoted the spread of Chinese culture. It is said that tea culture has always held a unique position under the background of "the Belt and Road Initiative". The construction of the tea culture communication system has injected new vitality into the international communication of Chinese culture. However, the construction of the system with Chinese characteristics is difficult at present, and the spread of tea culture is faced with a series of difficulties. This paper based on the perspective of "the Belt and Road Initiative" to build a system with Chinese characteristics with advanced technical means and novel system concepts, so as to enhance the influence of the international spread of Chinese tea culture.
\end{abstract}

\section{“一带一路”视角下构建中华特色茶文化传播体系}

\author{
汤明慧 \\ 中国计量大学,下沙,杭州,中国 \\ 1316572043@qq.com \\ 郭兰英
}

关键词：一带一路; 特色茶文化; 传播体系

中文摘要. “一带一路” 是我国提出的新型合作模式, “一带一路” 倡议为中华文化走向世界 开辟了广阔空间。我国古丝绸之路贸易中的重要商品就是中国茶，中国茶的贸易促进了我国 文化的对外传播。在 “一带一路” 的背景下，茶文化始终占有独特的地位。茶文化传播体系 的构建为中华文化对外传播注入新的活力。但当前中国特色茶文化传播体系构建难度较大, 茶文化传播事业面临着一系列困境。本文基于既有研究基础，基于 “一带一路” 视角，构建 技术手段先进、体制观念新颖的中华特色茶文化传播体系，以期提升中华茶文化国际化传播 的影响力。

\section{1. 引言}

党的十九大报告中指出, 推进国际传播能力建设, 讲好中国故事, 向世界展示真实、立 体的中国。实现中华民族伟大复兴不仅要依靠中国经济的可持续发展, 也要依靠中国建立起 传统文化的传播体系。“一带一路” 倡议为茶文化向世界传播提供了新的机遇。加强中华特 
色茶文化体系传播建设，有助于在 “一带一路” 建设中真实有效地向世界展现中华民族悠久 历史所积淀的灿烂文化，对于推动文化发展具有深远意义。与此同时，如何构建系统的茶文 化传播体系，有效地传播中国茶文化，已经成为亟待解决的时代课题。

\section{2. “一带一路” 视角下构建中华特色茶文化传播体系的意义}

在全球化时代，文化作为综合国力的重要体现，其地位日益突出。国际政治、经济的竞 争归根结底都表现为文化的竞争，只有实现文化可持续发展，才能保证国家与民族发展的可 持续性（闻竞，2019）。茶文化体现着中国传统文化的精髓，构建中华特色茶文化传播体系 事关中国特色、中国风格的话语体系创新。

习近平总书记指出，要 “把中华优秀传统文化传播到五湖四海”。把具有中华文化特征 的茶叶一直被作为礼物赠予外国使者这种行为由来已久。“一带一路” 的建设承担着让茶文 化走向世界的重要历史使命。中华茶文化的海外传播能够不断提升中国的文化软实力, 促进 中华茶文化产业的国际化水平，使区域内的国家联系更为紧密。而 “一带一路” 沿线人民也 将逐步加深对中华茶文化的理解，增加对中华文化的认同感。

\section{3. 中华特色茶文化海外传播的困境}

中国经济实力的不断增强，中国茶文化对外传播速度加快，茶文化的传播能力得到了巨 大提升。“一带一路” 倡议是一个宏伟的构想，其立足于我国历史文化和实际情况，在此基 础上建立的茶文化传播体系也有着极广的覆盖面。“一带一路” 战略的实施提供新时代背景 下中华茶文化海外传播良好平台，但中华特色茶文化传播事业依然面临着现实的困境。

\section{1 缺乏纲领性的对外传播文化体系}

随着中国 “文化热” 在国内外的不断升温, 越来越多的人对中华文化产生浓厚兴趣, 在 接触传统文化的过程中，各国人民加深了对中国的认识。但由于戏曲、音乐、文字、书籍、 剪纸、茶艺和工艺品等中华特色文化无法进行系统化和产品化, 大多以风俗形式流传, 其形 式在传承中渐显单一。而文化产业作为中华文化赖以生存的基础, 中华文化要想获得更强劲 的生命力与国际影响力, 就必须要大力推进文化制度改革。但目前而言, 文化产业的国际化 水平相对较低, 其占世界文化产业市场份额低。且缺乏大型专业的文化企业作为支撑, 文化 产业发展环境相对封闭, 缺乏纲领性的对外传播文化体系, 在文化市场中缺乏竞争力。张国 祚认为虽然我国整体传播实力得到很大增强, 但 “西强我弱” 的国际舆论格局没有实现根本 改变(张国祚，2011）。

\section{2 偪化传播模式和管理机制}

一个国家的文化传播力和影响力很大程度上取决于该文化本身的内涵，但如今很多茶文 化的传播仅留在表面, 中华特色茶文化在内容传播上面临着相对僵化和落后的问题。传统媒 体的信息生产周期较长，信息生产的时效性缺乏保障。随着经济全球化的深入发展，传统的 对外传播体系已难以满足 “一带一路” 沿线国家的文化诉求。中华文化海外传播已转向人际 传播。然而无论是业界还是政府主管部门, 都还停留在以外宣模式为主体、依靠大众媒介构 建中国对外文化传播体系层面。在实践发展远超以外宣为主的管理模式下, 出现一些具有广 泛传播效果的资源、传播手段、传播渠道没有充分调动起来的情况。以政府为主导的传播方 式极易流于形式，很难获得海外民众的真正认同，政府主导的文化传播理念制约着中国茶文 化的传播。 


\section{3 忽略华侨华人和志愿者的 “文化桥梁” 功能}

在中华茶文化的海外传播者中，华侨华人作为沟通中外文化的 “桥梁” ，在帮助中华茶 文化走出去方面有着独特的优势。华侨大学校长贾益民认为社会对于海外华侨华人必须有个 科学合理的定位, 充分利用好华侨华人这个社会资源, 让茶文化传播到世界更多的地方。此 外，研究志愿服务的专家丁元竹认为，国际志愿服务是一种 “民间外交”，国际志愿服务的 发展水平是一个国家 “软实力” 的重要体现。中华特色茶文化传播体系的构建需要充分调动 多元文化主体的积极性，但在中华特色茶文化海外传播的过程中由于忽略华侨华人的 “文化 桥梁”功能，使中国在国际传播中华特色茶文化中面临巨大挑战。

\section{4. “一带一路” 视角下构建中华特色茶文化传播体系的策略}

“一带一路”战略的实施为新时期中华特色茶文化的海外传播创造了良好的契机。以“一 带一路” 战略为依托, 充分挖掘中国传统文化的精粹, 构建中华特色茶文化传播体系。而 “一 带一路” 视角下的中华特色茶文化传播体系构建, 需创新传播方式和方法、改革与创新管理 机制、建立文化品牌机制、形成中华特色茶文化传播体系的基本纲领和发挥华侨华人的 “文 化桥梁” 作用。以期推动全方位、多层次的中华特色茶文化传播体系的建立，提高中华特色 茶文化对外传播的能力, 力求让世界不仅能够听到而且能够理解并接受中国的声音。

\section{1 构建中华特色茶文化传播体系的模式}

在信息泛滥的时代大背景下，建立文化品牌机制显得尤为重要。沃利・欧林斯说，“一 个品牌背后的核心概念, 必须兼备理性与感性的吸引力, 必须与众不同, 最后, 它必须真实。” 这句话简明而犀利地点出了品牌的核心，即真实、个性和吸引力。因此，地方政府在塑造茶 文化品牌时应遵循以中国的优秀文化为底蕴, 凸显出茶文化的独特个性, 增加其对人们的吸 引力。例如打造茶文化旅游品牌, 开展茶博会等活动形成自己的文化品牌机制。文化产品的 输出和文化品牌的打造, 会在无形之中巩固中国文化的世界地位。

“一带一路”倡议使不同国家间的交流更为频繁，杨通俊认为打造独具中国特色的茶文 化品牌需加强茶文化产品的对外输出, 积极培养文化人才, 让文化产品经营者设计出更多大 众所需的中国文化产品, 由此增强中国文化的跨地域、跨国界影响力。通过培养一批文化产 品经营者, 进行文化产品开发与供给, 形成文化产业链服务。茶文化产品经营者可通过建立 中国地域茶文化体验厅, 搭建高端茶文化交流平台, 开展茶文化学术交流会等, 向海外受众 传达中国文化精神，有效提升海外对中国传统文化的理解。

中华特色文化传播体系基本纲领的形成有助于中华特色文化更好的走出国门。我国文化 产业相关企业和从业者, 可以利用现代媒体手段, 深入挖掘中国传统文化的精髓, 创造更具 时代特色的文化产品。为形成中华特色文化传播体系的基本纲领, 政府部门应消除文化产业 经营堡垒, 营造更开放的文化产业发展环境; 做好文化产业监管机制与政策供给, 营造公平 公正的文化产业环境, 完善文化作品产权保护; 促进公共文化服务发展, 巩固文化产业发展 基础（梁怀新，2017）。

\section{2 创新传播方式和方法}

习近平总书记在谈到对外传播时重点强调了 “创新的对外传播模式”。这就要求在中华 特色茶文化的对外传播过程中, 用海外读者易接受方式, 讲述好中国故事。社会信息化的今 天, 新媒体手段成为文化走出国门的重要形式。多媒介融合是世界传媒业不断壮大发展的基 本规律, 新旧媒体的融合创造了一种新的传播范式和路径, 而且更加快速便捷地呈现出中华 文化的深刻内涵（纪希，2017）。其次，充分利用新媒体手段，搭建多平台传播渠道，通过 多种形式传播茶文化。早期中国各类传媒企业, 因各种原因, 直到20世纪末才开始进行大规 模体制改革, 时至今日依然处于产业转型的 “阵痛”之中。此外, 将主流媒体进行身份包装, 
以通俗的方式让文化 “走出去” 。让文化产业链协调互动、全行业参与文化竞争; 建设中华 文化传播示范区, 定期举行学术论坛和辩论大赛, 从中领略中华特色文化。

\section{3 发挥华侨华人的 “文化桥梁” 作用}

华侨华人是指生活在国外的中国人和具有中国人血统的外国人的总称。随着中国国际地 位的日益提升, 国外媒体和公众渴望了解中国悠久的文化文明。可以说, 海外华侨华人对于 中国的软实力构建具有基础性意义, 他们在一定程度上既是中华文化的载体, 又是一个中国 国家形象的载体。他们虽久居国外，但是根在中国使得他们天生就是中华茶文化的承载者、 创新者和传播者。随着华侨华人的政治地位不断增强, 华人社团的力量不断壮大, 中华特色 茶文化传播体系也在逐渐地形成。文化传播主体要求自身具有深厚中国传统文化修养，华人 华侨传播茶文化的方式主要有: 将茶文化融于日常的行为方式中, 比如通过喝茶方式展示中 国传统茶文化内涵; 将文化传播行为融入与传播对象的日常交往，在交流的同时让他人发现 中华文化的独特鬼力; 组建民间茶文化交流俱乐部之类的公益性社团组织。

\section{5. 结语}

中国作为一个正在崛起的大国，拥有广阔的舞台展现优秀的中华传统文化。构建中华特 色茶文化传播体系直接关乎到中华民族的世界地位，“一带一路” 的建设为进一步扩大对外 文化贸易提供了丰富的题材。本文分析了 “一带一路” 下构建中华特色茶文化传播体系的意 义以及中华特色文化海外传播的困境, 旨在寻求构建中华特色茶文化传播体系的策略, 提高 中华特色茶文化对外传播的能力和实际影响力。

在 “一带一路” 战略背景下，充分利用新媒体手段，增加中华文化海外传播路径，扩大 中华特色茶文化的覆盖面。找准文化定位, 创新传播方式和方法, 改革与创新管理机制, 建 立文化品牌机制，形成中华特色茶文化传播体系的基本纲领，营造良好的社会文化环境，发 挥华侨华人的“文化桥梁”作用，构建中华特色茶文化传播体系。

\section{References}

[1] Cailiang. An exploration of the mode of communication of Chinese culture for foreigners in China, China Radio\& TV Academic Journal, pp. 60-62, 2015.

[2] Guan Wenhu. National Image Theory[M]. University of Electronic Science and Technology Press, 2000.

[3] He Mingxing. Build a communication system for Chinese culture to enhance its communication capability, China Publishing Journal, pp.6-8, 2013.

[4] Liang Huaixing. Study on overseas communication of Chinese culture from the perspective of "the Belt and Road Initiative", ZHONGGONG SHIJIAZHUANG SHIWEI DANGXIAO XUEBAO, vol.19, pp. 35-38, 2017.

[5] Liu Weidong, Linjing. Build a communication system of strategic culture with Chinese characteristics. Modern Communication, vol. 185, pp. 17-21, 2018.

[6] Sun Haiyi. Study on the communication and translation of tea culture under the background of "the Belt and Road Initiative", Tea in Fujian, pp. 17-21, 2019.

[7] Wang Lingling. How to construct Chinese cultural communication system under "the Belt and Road Initiative", People's Tribune, vol. 59, pp. 136-137, 2016. 
[8] Wangdong. Study on overseas communication of Chinese characteristic culture from the perspective of "the Belt and Road Initiative", Education Modernization, vol. 102, pp. 222-223, pp.248, 2016.

[9] Yang Tianyu. Translation of Rites[M]. Shanghai : Shanghai Classics Publishing House, 2014.

[10] Yang Tongjun. The construction of Chinese cultural communication system under the background of "the Belt and Road Initiative". People's Tribune, vol. 65, pp. 140-141, 2017.

[11] Zhang Xuehui, Jiang Zuodong. A study on the role of overseas Chinese in China, Overseas Chinese Journal of BaGui, pp. 18-22,1997.

[12] Zhang Guozuo. Chinese cultural soft power research report[M]. Beijing : Social Sciences Academic Press (China), 2011. 